\title{
Comparative Paraquat Sensitivity of Newly Germinated and Mature Fronds of the Aquatic Macrophyte Spirodela polyrhiza
}

\author{
Jihae Park1, Hojun Lee ${ }^{1,2}$, Taejun Han ${ }^{2 *}$ \\ ${ }^{1}$ Lab of Plant Growth Analysis, Ghent University Global Campus, Incheon, Republic of Korea \\ ${ }^{2}$ Department of Marine Science, Incheon National University, Incheon, Republic of Korea \\ Email: ^hanalgae@inu.ac.kr
}

How to cite this paper: Park, J., Lee, H. and Han, T. (2020) Comparative Paraquat Sensitivity of Newly Germinated and Mature Fronds of the Aquatic Macrophyte Spirodela polyrhiza. American Journal of Plant Sciences, 11, 1008-1024.

https://doi.org/10.4236/ajps.2020.117072

Received: June 4, 2020

Accepted: July 10, 2020

Published: July 13, 2020

Copyright $\odot 2020$ by author(s) and Scientific Research Publishing Inc. This work is licensed under the Creative Commons Attribution International License (CC BY 4.0).

http://creativecommons.org/licenses/by/4.0/

\begin{abstract}
Here, we compared the intrinsic characteristics of 3-day-(newly germinated; "young") and 8-week-old ("mature") fronds of the aquatic plant Spirodela polyrhiza and their sensitivity to paraquat, a toxic herbicide. Endpoints measured were frond area and fresh weight, root length, chlorophyll $a$ and $b$ contents, and chlorophyll a fluorescence. Significant differences were detected in the intrinsic physiological traits between young and mature fronds. Young fronds showed higher root length, chlorophyll contents, maximum quantum yield $\left(F_{v} / F_{m}\right)$, maximal relative electron transport rate $\left(\mathrm{rETR}_{\max }\right)$ and saturating photon flux density (PFD), whereas mature fronds exhibited greater frond area and fresh weight. After a $72 \mathrm{~h}$ exposure to paraquat, root length and $\mathrm{rETR}_{\max }$ were identified as the most sensitive endpoints of paraquat toxicity for both frond types, with $\mathrm{EC}_{50}$ values of 0.66 and $0.76 \mu \mathrm{g} \cdot \mathrm{L}^{-1}$ for young fronds, respectively, and 5.53 and $2.28 \mu \mathrm{g} \cdot \mathrm{L}^{-1}$ for mature fronds, respectively. Young fronds of $S$. polyrhiza showed significantly higher sensitivity to paraquat than mature fronds. A survey of other studies on paraquat toxicity to Lemna species revealed that $\mathrm{EC}_{50}$ values of paraquat-induced inhibition of root regrowth and $\mathrm{rETR}_{\max }$ in both stages were the lowest, indicating that these two endpoints were the most sensitive to paraquat. In addition, $\mathrm{EC}_{50}$ values of both endpoints of mature fronds of $S$. polyrhiza appear to be similar to the current allowable concentrations in drinking water set by the World Health Organization (WHO), indicating that these values may have application for the assessment of toxicity risk of paraquat in aquatic ecosystems.
\end{abstract}

\section{Keywords}

Spirodela polyrhiza, Paraquat, Herbicide, Chlorophyll Contents, Chlorophyll a Fluorescence, Root Length 


\section{Introduction}

Herbicides are a class of chemical pesticides that are widely used to remove or control nuisance plants in agriculture and horticulture [1]. Residues amounting to $99.7 \%$ of the applied load are dispersed and enter the aquatic environment through run-off and leaching with damaging consequences for ecosystem health [2].

Paraquat, N,N-dimethyl-4,4-bipyridinium dichloride, is one of the most widely used ionic herbicides for controlling the growth and spread of broadleaved weeds, grasses and aquatic weeds. Contamination of water courses and lakes leads to its rapid accumulation by aquatic organisms, and especially fish [3]. It is a systemic herbicide that is highly toxic to plants, as it diverts electrons away from the donor side of the photosystem I (PSI) complex by accepting electrons from iron-sulphur (Fe-S) centres and/or ferredoxin, thus preventing electron transfer to NADP [4]. Oxidation of paraquat generates highly phytotoxic reactive oxygen species (ROS) such as superoxide anion $\left(\mathrm{O}_{2}^{-}\right)$, hydroxyl radicals $(\cdot \mathrm{OH})$, and hydrogen peroxide $\left(\mathrm{H}_{2} \mathrm{O}_{2}\right)$ [5]. Paraquat is also potentially lethal to a wide variety of non-target organisms, particularly primary producers [6] [7]. There is growing concern over the exposure to small quantities of paraquat in the aquatic environment, as it may have negative impacts on the endocrine systems of humans and wildlife. Therefore, continued monitoring of the levels and persistence of paraquat in the environment is urgently needed [8]. Despite its use being prohibited in several countries (e.g. throughout Europe) it continues to be manufactured and exported to various nations, globally [9]. As weeds become resistant to the world's most popular weed killer, Roundup, paraquat has been marketed as an alternative, with seven million pounds of paraquat being used in the United States on nearly 15 million hectares

(https://www.nytimes.com/2016/12/20/business/paraquat-weed-killer-pesticide. $\underline{\mathrm{html}}$. A recent report suggests that paraquat be closely related to a less immediately apparent effect-Parkinson's disease [10].

Therefore, determination of the presence of paraquat is still important for conducting a risk assessment of aquatic ecosystems. Chemical analysis of the environmental matrix is the most direct approach to reveal the status of contamination, of which reversed-phase high performance liquid chromatography (HPLC) with ultraviolet (UV) detection is considered a particularly sensitive technique for the determination of paraquat levels. However, conventional chemical analyses have several drawbacks, such as complex procedures of sample preparation and the need for expensive chemicals and equipment. In addition, most chemical analyses do not provide ecologically relevant information on the temporal changes or interactive effects of pollutants [11]. Moreover, paraquat is usually used in small quantities (1.0 - 5.0 ppm) and, therefore, the concentrations of paraquat residues in water are extremely low [12].

Aquatic bioassays are an important means of assessing the quality of water containing pollutants (both mixtures of pollutants and unknown pollutants) and 
are useful for providing safety standards for water management in an ecological context. Many different species of plants and protists have been used as test organisms, but primary producers are of paramount importance for monitoring the functioning and health of ecosystems. Since the 1940s, duckweed (Lemnaceae) has been extensively used as a model organism for conducting fundamental and applied research in environmental sciences, particularly phytotoxicity testing and bioremediation, and has also been used as a bioresource [13] [14] [15]. Duckweeds are commonly found in freshwater and brackish ecosystems in temperate climates and serve not only as an important food source for various water birds and fish, but also as habitats for small invertebrates. Most ecotoxicological studies conducted to date focus on duckweeds belonging to the genus Lemna, and in particular L. gibba and L. minor [16].

Recently, a toxicity test based on growth (change in area) inhibition of 3 day-old Spirodela fronds germinated from turions has recently been proposed for the International Organization for Standardization (ISO 20227) [17]. During its life cycle, Spirodela produces turions (meaning "shoot"), a type of buds that come from modified shoot apices and are often rich in starch and sugar, so that they can act as storage organs (Figure 1). Turions are known to be produced in response to adverse conditions such as decreasing day length or falling temperature [18]. Turions sink to the bottom of a pond or lake and hibernate when the water freezes, but rise again to germinate and grow into complete plants in spring.

The Spirodela test had similar levels of sensitivity to the Lemna test (ISO 20079) for nine herbicides, four inorganic and organic compounds and nine metals [17]. Results from a study by Oláh et al. [19] indicated differential sensitivity of turions and mature fronds to three metals (cadmium (Cd), chromium $(\mathrm{Cr})$ and nickel $(\mathrm{Ni})$ ), with higher tolerance levels for turions than normal fronds. Thus, further investigation of the relative sensitivity of plants of different ages and at different life stages is required.

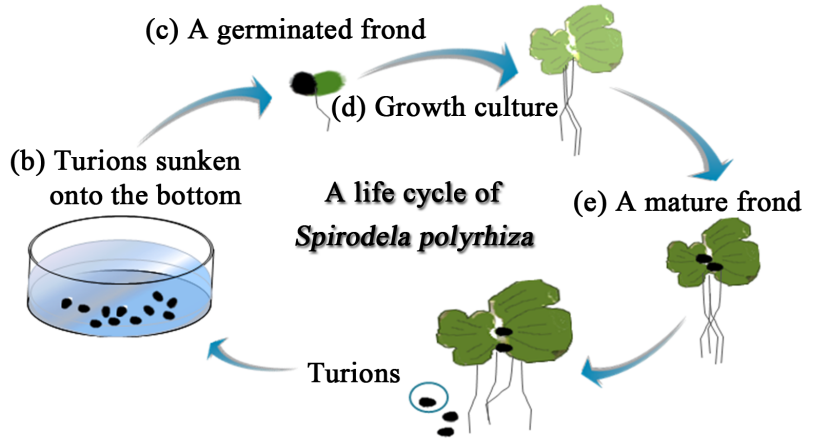

(a) Production of turions

Figure 1. The lifecycle of Spirodela polyrhiza. This plant forms a dormant stage, turion, during the dormant phase (a); after artificial germination of the turion sank to the bottom (b); germinated turoin forms young fronds (c) and these are cultivated under optimal conditions (d); then they grow back in the mature stage (e) and repeat their lifecycle. 
The appropriate selection of the assessed endpoints in (phyto) toxicity tests is the key factor for a successful and valid test result. Conventional toxicity testing methods (ISO20079) have employed numerous endpoints including: frond number, plant number, root number, dry or fresh biomass, root length, frond diameter, carbon uptake and chlorophyll (Chl) content [20]. Chlorophyll a fluorescence of photosystem II (PS II) reaction centres, a rapid and sensitive tool for evaluating toxicity in algae and higher plants [21] [22], has also been successfully used in Lemna tests [23].

Recently, Park et al. [13] reported a well-defined toxicant concentration-dependent inhibition of root regrowth for three Lemna species. This method has several operational advantages over other conventional techniques (ISO20079); for example, it requires a shorter duration $(72 \mathrm{~h})$, smaller test solution volume (approximately $3.0 \mathrm{~mL}$ ) and use of non-axenic plant material.

Depending on the circumstances, fronds germinated from turions may be stored in the laboratory for a long time before testing. It is therefore important to ascertain whether frond samples retrieved from long-term storage are suitable material for tests. The prospective ERA for herbicides has for many years been based exclusively on Lemna sp. as the only aquatic macrophyte, although it has only relatively recently been extended to dicotyledonous submerged macrophytes such as Myriophyllum sp. The inclusion of new monocotyls such as Spirodela as a test battery for herbicide toxicity may therefore not be an overpaid attempt. In this study, we aimed to: 1) compare the intrinsic physiological traits and paraquat sensitivity of 3-day-(young) and 8-week-old (mature) $S$. polyrhiza fronds germinated from turions, based on measurements of frond area and fresh biomass weight, root regrowth, pigment ( $\mathrm{Chl} a$ and $\mathrm{Chl} b$ ) content and $\mathrm{Chl} a$ fluorescence, 2) verify the inter-relationship between the tested endpoints in response to paraquat exposure; 3 ) evaluate whether extremely low concentrations of paraquat in aquatic ecosystems exert toxicological action on $S$. polyrhiza; and 4) evaluate whether the endpoints employed were sensitive enough to detect the toxic action of paraquat.

\section{Methods and Materials}

\subsection{Sample Collection and Maintenance}

Mature plants of Spirodela polyrhiza (L.) Schleiden were collected from the Upo wetland located at Changnyeong-gun, Gyeongsangnam-do, Korea ( $35^{\circ} 34^{\prime} 05^{\prime \prime} 60 \mathrm{~N}$, $\left.128^{\circ} 24^{\prime} 06^{\prime \prime} 90 \mathrm{E}\right)$. Fronds were maintained in a $1.5 \mathrm{~L}$ glass tank containing Steinberg medium [24] at $25^{\circ} \mathrm{C}$ under continuous white light (30 - $40 \mu \mathrm{mol}$ photons $\mathrm{m}^{-2} \cdot \mathrm{s}^{-1}$ ) supplied by cool daylight fluorescence tubes (FL $20 \mathrm{SS} / 18 \mathrm{D}$, Philips). The medium was replaced regularly at 7 day intervals, and its $\mathrm{pH}$ was adjusted to $6.9 \pm 0.2$ using either $1 \mathrm{M}$ hydrochloric acid $(\mathrm{HCl})$ or $1 \mathrm{M}$ sodium hydroxide $(\mathrm{NaOH})$.

To induce the production of turions, $1.0 \mathrm{~L}$ culture flasks were stored at $15^{\circ} \mathrm{C}$ for 4 - 6 weeks. Upon induction, each turion was separated from its mother frond 
[25]. All turions were then collected from the bottom of the flasks and transferred to $50 \mathrm{~mL}$ Falcon tubes containing Steinberg medium. The Falcon tubes were covered with foil, and the stock seed banks were stored at $4^{\circ} \mathrm{C}$ until needed for tests.

\subsection{Toxicity Test}

Prior to the tests, turions were germinated in Petri dishes $(85.6 \mathrm{~mm} \times 12.6 \mathrm{~mm})$ containing Steinberg medium at $25^{\circ} \mathrm{C}$ under continuous light (photon irradiance of $90-100 \mu \mathrm{mol}$ photons $\mathrm{m}^{-2} \cdot \mathrm{s}^{-1}$ ). Fronds germinated from turions were maintained under the same environmental conditions for either 3 days or 8 weeks. Just prior to experimentation, roots were cut from all fronds using stainless steel scissors and an individual rootless plant was added to each well of a 24-well plastic plate $(85.4 \times 127.6 \mathrm{~mm}$; well diameter, $15.6 \mathrm{~mm}$; SPL, Seoul, Korea). There were 4 plants per paraquat concentration, 6 concentrations per plate and three replicate plates $(\mathrm{n}=3)$. Different nominal concentrations of paraquat (Table 1) were prepared by diluting the original stock solutions (CAS No. 1910-42-5) with Steinberg medium. To perform the toxicity tests, a $3.0 \mathrm{~mL}$ test solution was added to each well. Tests were run for $72 \mathrm{~h}$ in an environmentally controlled chamber maintained at $25 \pm 1{ }^{\circ} \mathrm{C}$ and continuous light $(100 \pm 10 \mu \mathrm{mol}$ photons $\mathrm{m}^{-2} \cdot \mathrm{s}^{-1}$ ). Static tests were performed, i.e. the test solutions were not renewed during the period of exposure. A fully randomized design was used to account for any variability in environmental conditions within the culture chamber.

\subsection{Physiological Traits of Intrinsic Fronds and Responses to Paraquat Exposure}

\subsubsection{Frond Area, Weight and Regrown Root Length}

Fronds maintained for 3 days or 8 weeks with no other experimental treatments were randomly selected for comparison of their intrinsic physiological traits. Following the $72 \mathrm{~h}$ exposure to different concentrations of paraquat, $S$. polyrhiza fronds with regrown roots were picked using tweezers and placed upside-down on a glass slide. Because the fronds are wet, roots could be easily straightened with a light touch. Photographs of the fronds with regrown roots were captured using image analyser (e.g. Image J); the length of the longest root was measured to evaluate the root regeneration ability of fronds following paraquat exposure. The justification for why only the longest root to measure was to see the response of the fronds that will regenerate their first root becoming longest.

Table 1. Final concentration range and mode of action used for testing toxicity of paraquat with 2 ages of Spirodela polyrhiza.

\begin{tabular}{ccccc}
\hline \multirow{2}{*}{ CAS No. } & Physiological site & Molecular targets & \multicolumn{2}{c}{ Concentrations range $\left(\mu \mathrm{g} \cdot \mathrm{L}^{-1}\right)$} \\
\cline { 3 - 4 } & & Young & Mature \\
\hline $1910-42-5$ & Photosynthesis & PSI $^{*}$ electron acception & $0.09-1.563$ & $3.125-50$ \\
\hline
\end{tabular}

${ }^{*}$ Photosystem I. 
Fronds were then dried on a paper towel and weighed to determine their fresh biomass.

\subsubsection{Chl Contents}

Chl $a$ and $b$ contents $\left(\mu \mathrm{g} \cdot \mathrm{mL}^{-1}\right)$ were calculated using the following equation [26]:

$$
\begin{aligned}
& \text { Chl } a\left(\mu \mathrm{g} \cdot \mathrm{mL}^{-1}\right)=\left(15.65 \times A_{666}\right)-\left(7.34 \times A_{653}\right) \\
& \operatorname{Chl} b\left(\mu \mathrm{g} \cdot \mathrm{mL}^{-1}\right)=\left(27.05 \times A_{653}\right)-\left(11.2 \times A_{666}\right)
\end{aligned}
$$

where $A_{666}$ and $A_{653}$ represent the absorbance at 666 and $653 \mathrm{~nm}$. Based on the $\mathrm{Chl}$ content of the extract, the Chl content per gram of frond fresh biomass was calculated.

\subsubsection{Chl $a$ Fluorescence}

Chl a fluorescence was measured using an Imaging PAM (Walz, Germany), as a proxy for photosynthetic performance. To measure $F_{v} / F_{m}$ and $\mathrm{rETR}_{\max }$, samples were incubated in the dark for $10-15 \mathrm{~min}$. Pulses $\left(0.15 \mu \mathrm{mol}\right.$ photons $\left.\mathrm{m}^{-2} \cdot \mathrm{s}^{-1}\right)$ from light emitting diodes (LED) were used to determine the initial fluorescence yield $\left(F_{o}\right)$, which denotes the fluorescence yield when all photosystem II (PSII) reaction centres are open, with fully oxidized plastoquinone $A\left(Q_{A}\right)$. Then, a saturation pulse of approximately $5000 \mu \mathrm{mol}$ photons $\mathrm{m}^{-2} \cdot \mathrm{s}^{-1}$ emitted by an LED lamp was applied to produce the maximum fluorescence yield $\left(F_{m}\right)$, which is induced by a short saturating pulse of actinic light that reduces all $\mathrm{Q}_{\mathrm{A}}$ molecules. The value of $F_{v} / F_{m}$ was then calculated using the following equation:

$$
F_{v} / F_{m}=\left(F_{m}-F_{o}\right) / F_{m}
$$

where $F_{v}$ is the variable fluorescence.

Rapid light curves were produced using 10s pulses of actinic light increased stepwise from 0 to $1517 \mu \mathrm{mol}$ photons $\mathrm{m}^{-2} \cdot \mathrm{s}^{-1}$ [27]. Effective quantum yield $\left(\Phi_{\mathrm{PSII}}\right)$ was calculated using the following equation:

$$
\Phi_{\mathrm{PSII}}=\left(F_{m}^{\prime}-F\right) / F_{m}^{\prime}
$$

where $F_{m}^{\prime}$ is the maximum light-acclimated fluorescence yield, and $F$ is the light-acclimated fluorescence yield.

The maximum electron transport rate $\left(\mathrm{ETR}_{\max }\right)$ was calculated using the hyperbolic tangent equation adapted from Jassby and Platt [28]:

$$
\mathrm{rETR}=\operatorname{ETR}_{\text {max }} \times \tanh \left(a I / \operatorname{ETR}_{\max }\right)
$$

where $\alpha$ and $I$ indicate ETR and PFD, respectively, under light limiting conditions.

\subsection{Statistical Analysis}

Data were analyzed using one-way analysis of variance (ANOVA) at a significance level of $\mathrm{P}<0.05$, after homogeneity test. To determine differences among treatments, post-hoc comparisons were performed using the least significant dif- 
ference (LSD) test. Toxicity test results were reported as $\mathrm{EC}_{50}$ values (effective concentration at which $50 \%$ inhibition occurs), with $95 \%$ confidence intervals estimated using the linear interpolation method (ToxCalc 5.0; Tidepool Science, California, USA).

\section{Results and Discussion}

\subsection{Turion Germination}

Determination of the optimal conditions for turion germination is important since several environmental factors can simultaneously influence germination of the turions of $\mathcal{S}$. polyrhiza [29], but standardization of optimal germination for toxicity testing has not yet been established [17]. The germination of $S$. polyrhiza under different photon irradiances, $\mathrm{pH}$ and temperatures is shown in Figure 1. Turions germinated in all light levels from 5 to $100 \mu \mathrm{mol}$ photons $\mathrm{m}^{-2} \cdot \mathrm{s}^{-1}$ but not in the dark (Figure 2(a)); turion germination is light dependent normally [30]. The maximal germination was recorded at $\mathrm{pH} 5$ and 7 but at $\mathrm{pH} 3$ no germination was observed (Figure 2(b)). There was $100 \%$ germination of turions at $25^{\circ} \mathrm{C}$ and $30^{\circ} \mathrm{C}$ but there was no evidence of germination at either $5^{\circ} \mathrm{C}$ or $15^{\circ} \mathrm{C}$ (Figure $2(c))$.

In nature, germination of Spirodela turions is controlled by temperature and light [31], although exposure to combinations of red and far-red light, long photoperiods, gibberellin and kinetin (plant hormones) can accelerate the germination process [32] [33] [34]. In laboratory studies, turion germination was found to be controlled by exposure to temperature and light of $22^{\circ} \mathrm{C}-25^{\circ} \mathrm{C}$ and 60 to $120 \mu \mathrm{mol}$ photons $\mathrm{m}^{-2} \cdot \mathrm{s}^{-1}$ for 3 - 7 days [17] [19].

It has been observed that turions float to the water surface by formation of internal oxygen bubbles prior to their germination [30] [35]. Photosynthetic activities thus appear to be involved in the germination process since turion surfacing may be geared by photosynthetic $\mathrm{O}_{2}$ production, which is also affected by bicarbonate concentrations as a major aquatic carbon source [31]. In this respect, temperature and $\mathrm{pH}$ would be influential factors for initiation of germination since the amount of carbon (as $\mathrm{CO}_{2}$ or $\mathrm{H}_{2} \mathrm{CO}_{3}$ ) in the water is dependent on these

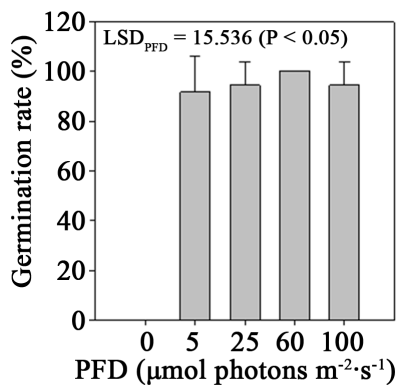

(a)

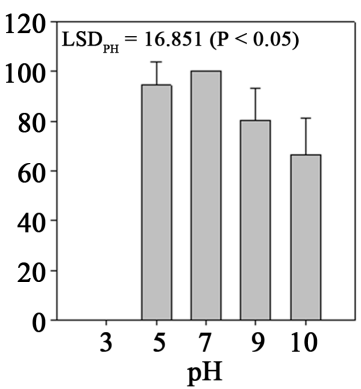

(b)

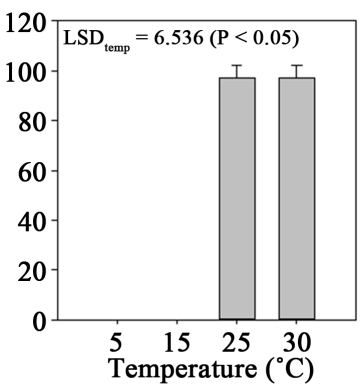

(c)

Figure 2. Effects of photon flux density (PFD) (a); $\mathrm{pH}$ (b) and temperature (c) on the germination of turion in Spirodela polyrhiza. The bar denotes mean values and error bar indicates the standard deviation. LSD shows the least significant difference at the $5 \%$ level. No bar indicates no germination. 
parameters. It is therefore interesting to note that germination reaches its maximum at $\mathrm{pH} 7$ where the availability of $\mathrm{H}_{2} \mathrm{CO}_{3}$ is at its greatest.

\subsection{Standard Conditions}

Environmental factors influence growth and photosynthetic activity of aquatic plants, with $\mathrm{pH}$, light and temperature being probably the most important parameters. It has been shown that these parameters also modify the toxic effects of chemical pollutants in aquatic plants [36]. Thus, it is important that the culture conditions under which toxicity tests are carried out are fully reported/disclosed and that the tests are, preferably, carried out under standardized conditions for a particular species and endpoints to be measured. For this reason, we first determined the optimal conditions for growth of fronds and roots of $S$. polyrhiza (Figure 3 and Figure 4). The maximal growth of both frond and root was recorded at $100 \mu \mathrm{mol}$ photons $\mathrm{m}^{-2} \cdot \mathrm{s}^{-1}$ and $25^{\circ} \mathrm{C}$ while no significant difference was observed in the range of $\mathrm{pH}$ between 4 and 10. It is interesting to note that there was some growth at low temperatures despite the lack of germination at these temperatures. Also, no growth was detected at temperatures lower than $10^{\circ} \mathrm{C}$. All these data appear to imply the existence of different control mechanisms for turion germination, frond growth and root regrowth.

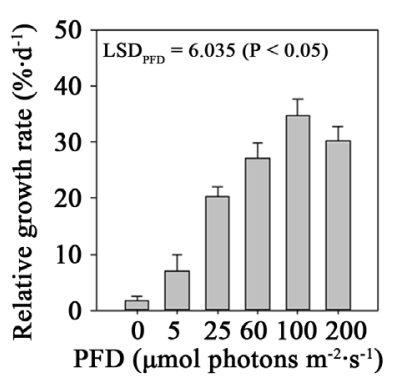

(a)

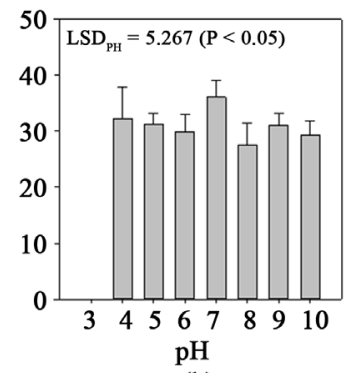

(b)

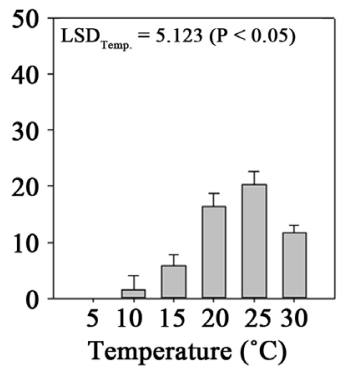

(c)

Figure 3. Effects of photon flux density (PFD) (a); pH (b) and temperature (c) on the relative growth rate $\left(\%, \mathrm{~d}^{-1}\right)$ of germinated fronds in Spirodela polyrhiza. The bar denotes mean values and error var indicates the standard deviation. LSD shows the least significant difference at the $5 \%$ level. No bar indicates that all samples are dead.

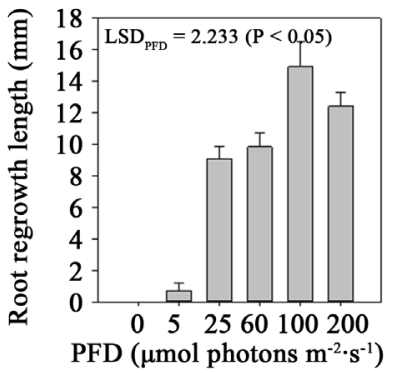

(a)

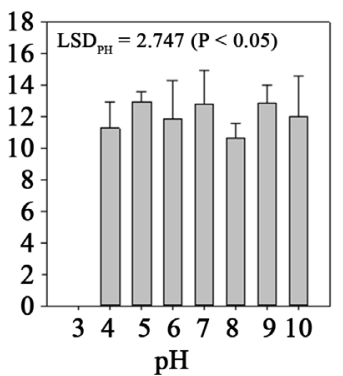

(b)

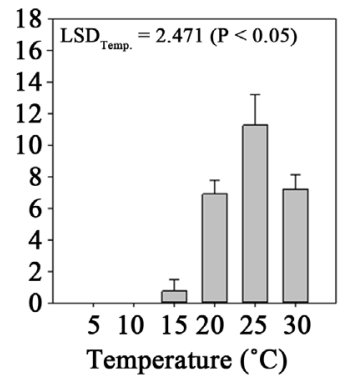

(c)

Figure 4. Effects of photon flux density (PFD) (a); $\mathrm{pH}$ (b) and temperature (c) on the root regrowth length $(\mathrm{mm})$ of germinated fronds in Spirodela polyrhiza. The bar denotes mean values and error var indicates the standard deviation. LSD shows the least significant difference at the $5 \%$ level. No bar indicates that all samples are dead. 


\subsection{Intrinsic Physiological Traits of Young and Mature Fronds in S. polyrhiza}

Different aged fronds (3 days and 8 weeks old) showed intrinsic differences in physiological traits (Table 2). The area and fresh weight of young fronds were approximately $19.06 \%$ and $29.35 \%$ that of mature fronds. However, roots of young fronds $(17.58 \pm 2.98 \mathrm{~mm})$ were longer than those of mature fronds $(11.98$ $\pm 3.23 \mathrm{~mm}$ ). No statistically significant differences were detected in Chl $a$ and Chl $b$ contents between young and mature fronds. When Spirodela fronds become mature, there are enlargements in the mesophyll cells with prominent intercellular spaces and air chambers in the abaxial surface of maturing fronds [37]. Morphological changes in the internal structure of fronds during development may explain the significantly larger frond area and weight in mature fronds than in newly germinated fronds.

Spirodela plants have simple, short and thin roots that lack branches and hairs [38], although the root systems of young and mature fronds have not been compared. Roots appear to serve an important role in balancing and maintaining the floating body in a stable and upright position [38]. Differences in root length between young and mature fronds might be explained by the higher photosynthetic capacity of young fronds. Thus, in young plants photosynthetic products are re-directed in favor of root production that provides the smaller and lighter floating fronds stable positioning.

On the other hand, we found significantly higher Chl $a$ and Chl $b$ content in young than in mature fronds, which was similar to the report made by Kim [39]. As the chlorophyll contents were calculated on a fresh weight basis, lower chlorophyll in mature fronds may be ascribed to higher proportion of non-photosynthetic structures such as intracellular spaces and air chambers.

Values of $F_{v} / F_{m}, \mathrm{rETR}_{\max }$ and $I_{K}$ of young fronds $(0.752 \pm 0.034,20.58 \pm 8.28$ and $122.34 \pm 47.64 \mu \mathrm{mol}$ photons $\mathrm{m}^{-2} \cdot \mathrm{s}^{-1}$, respectively) were significantly higher than those of mature fronds $(0.491 \pm 0.160,12.18 \pm 6.355$ and $71.22 \pm 26.28 \mu \mathrm{mol}$

Table 2. Physiological traits of young and mature fronds of $S$. polyrhiza.

\begin{tabular}{|c|c|c|c|c|c|c|c|}
\hline \multirow{2}{*}{ Parameters } & \multicolumn{2}{|c|}{ Young } & \multicolumn{2}{|c|}{ Mature } & \multirow{2}{*}{$\begin{array}{c}\text { Mean } \\
\text { difference }\end{array}$} & \multirow{2}{*}{ t-value } & \multirow{2}{*}{$\mathrm{P}$} \\
\hline & Mean & $\mathrm{SD}$ & Mean & SD & & & \\
\hline $\mathrm{FA}\left(\mathrm{mm}^{2}\right)$ & 13.49 & 5.38 & 70.78 & 14.37 & -57.29 & -12.934 & $0.000^{\star *}$ \\
\hline FW (mg) & 4.52 & 1.29 & 15.40 & 5.57 & -10.88 & -6.592 & $0.000^{\star *}$ \\
\hline $\mathrm{RL}(\mathrm{mm})$ & 17.58 & 2.98 & 11.98 & 3.23 & 5.6 & 4.414 & $0.000^{* *}$ \\
\hline Chl $a\left(\mathrm{mg} \cdot \mathrm{g}^{-1} \mathrm{FW}\right)$ & 1.29 & 0.22 & 1.16 & 0.19 & 0.137 & 1.662 & 0.111 \\
\hline $\mathrm{Chl} b\left(\mathrm{mg} \cdot \mathrm{g}^{-1} \mathrm{FW}\right)$ & 1.40 & 0.32 & 1.16 & 0.27 & 0.235 & 1.920 & 0.068 \\
\hline$F_{v} / F_{m}$ & 0.75 & 0.03 & 0.49 & 0.16 & 0.26 & 5.518 & 0.000 \\
\hline $\mathrm{rETR}_{\max }$ & 20.58 & 8.28 & 12.18 & 6.36 & 8.407 & 2.789 & $0.011^{\star}$ \\
\hline
\end{tabular}

FA; relative growth rate of frond area, FW; fresh weight, RL; root regrowth length, Chl $a$; chlorophyll $a$ content, Chl $b$; chlorophyll $b$ content, $F_{v} / F_{m}$; Optimal quantum yield, $\mathrm{rETR}_{\max }$; the maximum electron transport rate, $\mathrm{SD}$; standard deviation. ${ }^{*} \mathrm{P}<0.001 ;{ }^{*} \mathrm{P}<0.05$. 
photons $\mathrm{m}^{-2} \cdot \mathrm{s}^{-1}$, respectively). However, alpha values were similar between the two frond types ( 0.168 for young and 0.160 for mature fronds).

The maximum quantum yield of PSII chemistry $\left(F_{v} / F_{m}\right)$ is an estimate of the photochemical conversion efficiency of PSII in the dark. Higher values of $F_{v} / F_{m}$ indicate higher light utilization efficiency and greater ability to adapt to low light conditions [40]. Lemna spp. typically have $F_{v} / F_{m}$ maxima of about $0.68-0.73$ [11] [13]. Compared with Lemna spp., young fronds of $S$. polyrhiza were found to have similar $F_{v} / F_{m}$, but mature fronds showed lower $F_{v} / F_{m} . F_{v} / F_{m}$ values appear to be in line with chlorophyll contents in that $F_{v} / F_{m}$ was greater in young fronds with higher $\mathrm{Chl} a$ and $\mathrm{Chl} b$ than in mature fronds.

rETR is an empirical estimate of the rate of flow of electrons through the electron transport chain and $\mathrm{rETR}_{\max }$ is defined as the maximum rETR at saturating irradiance [40]. Higher $\mathrm{rETR}_{\max }$ in young fronds means that there is higher probability of a photochemical event resulting in more active and effective electron transport upon absorption of a photon by the antennae of PS II. The initial slope of a P vs $I$ curve represents the light-limited phase of photosynthesis, and its gradient is affected by the efficiency with which the plant can absorb the limited light available [41]. Saturation irradiance $\left(I_{k}\right)$ is defined as the point at which the extrapolated initial slope crosses $\mathrm{rETR}_{\max }$. Comparison of $\mathrm{rETR}_{\max }$, alpha and $I_{k}$ showed that the number of photosynthetic units (PSUs) but not the size of PSUs differed between young and mature fronds of $S$. polyrhiza since $\mathrm{ETR}_{\max }$ and $I_{k}$ values were higher while alpha values were the same [41]. Young fronds seem to have more PSUs than mature ones, and hence the higher FTR $_{\max }$ and $I_{k}$ values.

\subsection{Comparative Sensitivity of Young and Mature Fronds to Paraquat}

Paraquat sensitivity of $S$. polyrhiza fronds at both stages was dependent on the endpoints. After a $72 \mathrm{~h}$ exposure to paraquat, the most sensitive paraquat toxicity endpoints were root length and $\mathrm{rETR}_{\max }$ in both frond types, with $\mathrm{EC}_{50}$ values of $0.66 \pm 0.03$ and $0.76 \pm 0.09 \mu \mathrm{g} \cdot \mathrm{L}^{-1}$, respectively, in young fronds and $5.53 \pm 1.5$ and $2.28 \pm 0.39 \mu \mathrm{g} \cdot \mathrm{L}^{-1}$, respectively, in mature fronds (Table 3). Coefficients of variation for root re-growth and $\mathrm{rETR}_{\max }$ were $4.55 \%$ and $11.84 \%$, respectively, for young fronds and $27.12 \%$ and $17.11 \%$, respectively, for mature fronds (Table 3). Paraquat was reported to be one of the most toxic herbicides for Lemna spp. with $\mathrm{EC}_{50}$ values of $7.1-10.6 \mu \mathrm{g} \cdot \mathrm{L}^{-1}$ for root regrowth and $6.6-8.0 \mu \mathrm{g} \cdot \mathrm{L}^{-1}$ for $\mathrm{rETR}_{\max }$ [13]. The paraquat sensitivity of Spirodela was higher in young fronds and similar in mature fronds to that of Lemna spp.

It is notable that there was statistically significant difference in the sensitivity to paraquat toxicity between young and mature fronds, which would bring to question as to which stages, young or mature fronds would then be more suitable for toxicity testing. Sensitivity of bioassay methods is important for determination of whether to use them or not for water quality risk assessment. Effective bioassays should produce results within the relevant environmental ranges. 
Table 3. $\mathrm{EC}_{50}$ and $\mathrm{CV}$ values for inhibition of various parameters in two different ages (young and mature) of $S$. polyrhiza exposed to different concentrations of paraquat. Mean \pm standard deviation are shown ( $\mathrm{n}=3$ plates, 24 plants per plate with 4 plants per each concentration).

\begin{tabular}{|c|c|c|c|c|c|c|c|c|}
\hline \multirow{2}{*}{$\begin{array}{l}\text { Age after } \\
\text { germination }\end{array}$} & \multirow{2}{*}{$\begin{array}{l}\text { Toxic } \\
\text { units }\end{array}$} & \multicolumn{7}{|c|}{$\begin{array}{l}\text { Comparative sensitivities between young and mature } \\
\text { fronds in various parameters }\end{array}$} \\
\hline & & FA & FW & $\mathrm{RL}$ & Chl a & Chl $b$ & $F_{v} / F_{m}$ & $\mathrm{rETR}_{\max }$ \\
\hline \multirow[t]{2}{*}{ young } & $\begin{array}{c}\mathrm{EC}_{50} \\
\left(\mu \mathrm{g} \cdot \mathrm{L}^{-1}\right)\end{array}$ & $>1.56$ & $>1.56$ & $0.66 \pm 0.03$ & $>1.56$ & $>1.56$ & $>1.56$ & $0.76 \pm 0.09$ \\
\hline & CV (\%) & $N A$ & $N A$ & 4.55 & $N A$ & $N A$ & $N A$ & 11.84 \\
\hline \multirow{2}{*}{ mature } & $\begin{array}{c}\mathrm{EC}_{50} \\
\left(\mu \mathrm{g} \cdot \mathrm{L}^{-1}\right)\end{array}$ & $>50$ & $>50$ & $5.53 \pm 1.5$ & $42.86 \pm 1.53$ & $38.41 \pm 1.78$ & $12.67 \pm 4.32$ & $2.28 \pm 0.39$ \\
\hline & CV (\%) & $N A$ & $N A$ & 27.12 & 3.57 & 4.63 & 34.1 & 17.11 \\
\hline
\end{tabular}

FA; relative growth rate of frond area, FW; fresh weight, RL; root regrowth length, Chl $a$; chlorophyll a content, Chl $b$; chlorophyll $b$ content, $F_{v} / F_{m}$; Optimal quantum yield, $\mathrm{rETR}_{\max }$; the maximum electron transport rate, $\mathrm{EC}_{50}$; the effective concentration at which $50 \%$ inhibition occurs, $\mathrm{CV}$; coefficient of values, $N A$; not applicable.

A current guideline for the allowable concentrations in drinking waters set by WHO is $10 \mu \mathrm{g} \cdot \mathrm{L}^{-1}$ for paraquat. This study shows that endpoints of root length and $\mathrm{rETR}_{\max }$ in both young and mature frond of $S$. polyrhiza are sensitive enough to detect toxic impacts of water samples containing paraquat in excess of allowable guidelines. However, the sensitivity of young fronds is almost over 10 times the permissible levels of paraquat in drinking water, and unless even a slightest presence of paraquat should be monitored and prevented, mature fronds would more successfully be employed for management decisions. Spirodela methods also show a high level of precision and reproducibility which are essential for adoption of toxicity testing methods. A desirable level of repeatability expressed by CVs is 30\% or less according to Environment Canada (2007) [42]. For young and mature fronds with the endpoints of root length and $\mathrm{rETR}_{\max } \mathrm{CVs}$ for $\mathrm{EC}_{50}$ values were found to lie within this acceptable range (Table 3 ).

The ultimate goal of bioassay testing is to provide representative and inclusive criteria of exposure conditions, thereby improving risk assessment and water quality management. In this respect, multiple rather than single endpoint assays may have greater potential for a more comprehensive risk assessment of toxicants. Such an approach allows to gain important insights into the mechanisms of toxicity and to obtain information on the relative sensitivity of measured endpoints to toxicity concentration and/or exposure duration, thereby identifying specific endpoints that can effectively detect interferences caused by certain phytotoxics [43]. In the past, little attention has been paid to the roots in Lemna since it was generally considered that root fragility made their handling for measurements difficult and that it was impractical to obtain sufficient numbers of individual plants with identical root lengths to initiate tests. However, more recently the ecotoxicological significance of the root endpoint has been re-evaluated and root length is now considered to be a sensitive, precise and ecologically sig- 
nificant endpoint in comparison with more traditional frond growth and biomass endpoints [36] [44].

One of the most frequently used methods for monitoring the status of the photosynthetic apparatus in plants is in vivo chlorophyll a fluorescence, a nondestructive, straightforward and rapid technique that is applicable in both laboratory and field studies. It is used as a potential indicator of exposure to environmental and chemical stresses, including herbicides. The impact of certain herbicides, such as commonly used ones like diuron, atrazine and simazine, on the photochemical activity of PSII has long been recognized [45] [46] [47] [48]. Such PSII inhibitors restrict photosynthetic activity through their binding to the D1 protein in thylakoids and blocking electron transport through the PSII reaction center with effects being manifested by changes in various chlorophyll fluorescence parameters [49]. Frond area, fresh weight, root length, chlorophylls and chlorophyll a fluorescence have never been measured simultaneously as endpoints. Figure S1 shows correlative relationships between two different endpoints. There was a strong relationship between the frond area and weight and between $\mathrm{Chl} a$ and $\mathrm{Chl} b$ to a lesser degree in both young and mature fronds. It was notable that root length rather than frond growth was highly correlated with photosynthetic performance. Photosynthetic electron transport events support the biochemical reactions needed for plant growth since the electron transport rate is closely related to the photosynthetic activity including oxygen evolution or $\mathrm{CO}_{2}$ uptake [50]. Therefore, a direct or an indirect effect of a pollutant on photosynthetic processes is observed prior to an effect on the growth process [51]. Little relationship between PSII inhibition and frond growth may indicate possible detoxification of cells and recovery of growth, thereby the inhibition of PSII inhibition no longer reflecting the inhibition of growth [52]. In contrast, the close relationship between PSII inhibition and root re-growth may imply a direct or an indirect effect of a pollutant on photosynthetic processes observed prior to an effect on the root growth process [51].

\section{Conclusion}

We found intrinsic physiological traits difference between young and mature frond of $S$. polyrhiza: young fronds invest more photosynthetic products to develop root elongation and chlorophylls which might be an adaptive strategy for future development via active photosynthesis and stabilization of the body positioning using longer roots, whereas mature fronds tilt to increase frond area and weight via structural development. For organic xenobiotics in particular, such as paraquat and other artificial toxicants, there is evidence that some standardised endpoints, such as total growth, fresh or dry weight or number of individuals, may under- or overestimate the actual risk level, especially if the doses of the toxic compounds are sublethal. In many cases there are other valuable endpoints such as more detailed analyses of stress responses at the subcellular and biochemical levels, but these assessments are still quite expensive because of the 
probes and detection systems or laboratory equipment required and are not included in standardised toxicity tests. In this respect, our Spirodela root test with either turion germinated or mature fronds would be a valuable asset for the risk assessment of paraquat, as it is a technique that allows toxicity to be assessed more quickly and easily, but without loss of sensitivity.

\section{Acknowledgements}

This research was supported by a grant from Incheon National University Research (2015-1444).

\section{Conflicts of Interest}

The authors declare no conflict of interest.

\section{References}

[1] Fatima, M., Mandiki, S., Douxfils, J., Silvestre, F., Coppe, P. and Kestemont, P. (2007) Combined Effects of Herbicides on Biomarkers Reflecting Immune-Endocrine Interactions in Goldfish: Immune and Antioxidant Effects. Aquatic Toxicology, 81, 159-167. https://doi.org/10.1016/j.aquatox.2006.11.013

[2] Prado, R., García, R., Rioboo, C., Herrero, C., Abalde, J. and Cid, A. (2009) Comparison of the Sensitivity of Different Toxicity Test Endpoints in a Microalga Exposed to the Herbicide Paraquat. Environment International, 35, 240-247. https://doi.org/10.1016/j.envint.2008.06.012

[3] Gabryelak, T. and Klekot, J. (1985) The Effect of Paraquat on the Peroxide Metabolism Enzymes in Erythrocytes of Freshwater Fish Species. Comparative Biochemistry and Physiology_Part C: Toxicology \& Pharmacology, 81, 415-418. https://doi.org/10.1016/0742-8413(85)90030-1

[4] Babbs, C.F., Pham, J.A. and Coolbaugh, R.C. (1989) Lethal Hydroxyl Radical Production in Paraquat-Treated Plants. Plant Physiology, 90, 1267-1270. https://doi.org/10.1104/pp.90.4.1267

[5] Moustaka, J. and Moustakas, M. (2014) Photoprotective Mechanism of the Non-Target Organism Arabidopsis thaliana to Paraquat Exposure. Pesticide Biochemistry and Physiology, 111, 1-6. https://doi.org/10.1016/j.pestbp.2014.04.006

[6] Franqueira, D., Cid, A., Torres, E., Orosa, M. and Herrero, C. (1999) A Comparison of the Relative Sensitivity of Structural and Functional Cellular Responses in the Alga Chlamydomonas eugametos Exposed to the Herbicide Paraquat, Archives of Environmental Contamination and Toxicology, 36, 264-269. https://doi.org/10.1007/s002449900470

[7] Mensah, P.K., Palmer, C.G. and Muller, W.J. (2014) Lethal and Sublethal Effects of Pesticides on Aquatic Organisms: The Case of a Freshwater Shrimp Exposure to Roundup ${ }^{\oplus}$. In: Pesticides-Toxic Aspects, IntechOpen, London, 163-185. https://doi.org/10.5772/57166

[8] Zaranyika, M. and Nyoni, S. (2013) Degradation of Paraquat in the Aquatic Environment: A Proposed Enzymatic Kinetic Model That Takes into Account Adsorption/Desorption of the Herbicide by Colloidal and Sediment Particles. International Journal of Research in Chemistry and Environment, 3, 26.

[9] Hakim, D. (2016) This Pesticide Is Prohibited in Britain. Why Is It Still Being Exported. The New York Times, December, 20, 2016. 
[10] Vaccari, C., El Dib, R. and de Camargo, J.L.V. (2017) Paraquat and Parkinson's Disease: A Systematic Review Protocol According to the OHAT Approach for Hazard Identification. Systematic Reviews, 6, 98-98. https://doi.org/10.1186/s13643-017-0491-x

[11] Park, J.-S., Brown, M.T. and Han, T. (2012) Phenol Toxicity to the Aquatic Macrophyte Lemna paucicostata. Aquatic Toxicology, 106, 182-188. https://doi.org/10.1016/j.aquatox.2011.10.004

[12] Siemering, G. and Hayworth, J. (2005) A White Paper Submitted to the Interagency Ecological Program Contaminants Work Group.

[13] Park, J., Brown, M.T., Depuydt, S., Kim, J.K., Won, D.-S. and Han, T. (2017) Comparing the Acute Sensitivity of Growth and Photosynthetic Endpoints in Three Lemna Species Exposed to Four Herbicides. Environmental Pollution, 220, 818-827. https://doi.org/10.1016/j.envpol.2016.10.064

[14] Iqbal, J., Javed, A. and Baig, M.A. (2019) Growth and Nutrient Removal Efficiency of Duckweed (Lemna minor) from Synthetic and Dumpsite Leachate under Artificial and Natural Conditions, PLoS ONE, 14, e0221755. https://doi.org/10.1371/journal.pone.0221755

[15] Sońta, M., Rekiel, A. and Batorska, M. (2019) Use of Duckweed (Lemna L.) in Sustainable Livestock Production and Aquaculture-A Review. Annals of Animal Science, 19, 257-271. https://doi.org/10.2478/aoas-2018-0048

[16] Drost, W., Matzke, M. and Backhaus, T. (2007) Heavy Metal Toxicity to Lemna minor. Studies on the Time Dependence of Growth Inhibition and the Recovery after Exposure. Chemosphere, 67, 36-43. https://doi.org/10.1016/j.chemosphere.2006.10.018

[17] Baudo, R., Foudoulakis, M., Arapis, G., Perdaen, K., Lanneau, W., Paxinou, A.-C., Kouvdou, S. and Persoone, G. (2015) History and Sensitivity Comparison of the Spirodela polyrhiza Microbiotest and Lemna Toxicity Tests. Knowledge and Management of Aquatic Ecosystems, 416, 23. https://doi.org/10.1051/kmae/2015019

[18] Appenroth, K.J. and Nickel, G. (2010) Turion Formation in Spirodela polyrhiza: The Environmental Signals That Induce the Developmental Process in Nature. Physiologia Plantarum, 138, 312-320. https://doi.org/10.1111/j.1399-3054.2009.01319.x

[19] Oláh, V., Hepp, A. and Mészáros, I. (2015) Comparative Study on the Sensitivity of Turions and Active Fronds of Giant Duckweed (Spirodela polyrhiza (L.) Schleiden) to Heavy Metal Treatments. Chemosphere, 132, 40-46. https://doi.org/10.1016/j.chemosphere.2015.01.050

[20] Wang, W. (1990) Literature Review on Duckweed Toxicity Testing. Environmental Research, 52, 7-22. https://doi.org/10.1016/S0013-9351(05)80147-1

[21] Schreiber, U., Quayle, P., Schmidt, S., Escher, B.I. and Mueller, J.F. (2007) Methodology and Evaluation of a Highly Sensitive Algae Toxicity Test Based on Multiwell Chlorophyll Fluorescence Imaging. Biosensors and Bioelectronics, 22, 2554-2563. https://doi.org/10.1016/j.bios.2006.10.018

[22] Muller, R., Schreiber, U., Escher, B.I., Quayle, P., Nash, S.M.B. and Mueller, J.F. (2008) Rapid Exposure Assessment of PSII Herbicides in Surface Water Using a Novel Chlorophyll a Fluorescence Imaging Assay. Science of the Total Environment, 401, 51-59. https://doi.org/10.1016/j.scitotenv.2008.02.062

[23] Hulsen, K., Minne, V., Lootens, P., Vandecasteele, P. and Höfte, M. (2002) A Chlorophyll a Fluorescence-Based Lemna minor Bioassay to Monitor Microbial Degradation of Nanomolar to Micromolar Concentrations of Linuron. Environmental Microbiology, 4, 327-337. https://doi.org/10.1046/j.1462-2920.2002.00309.x 
[24] Steinberg, R.A. (1946) Mineral Requirements of Lemna minor. Plant Physiology, 21, 42. https://doi.org/10.1104/pp.21.1.42

[25] Appenroth, K.J., Palharini, L. and Ziegler, P. (2013) Low-Molecular Weight Carbohydrates Modulate Dormancy and Are Required for Post-Germination Growth in Turions of Spirodela polyrhiza. Plant Biology, 15, 284-291. https://doi.org/10.1111/j.1438-8677.2012.00637.x

[26] Lichtenthaler, H.K. and Wellmurn, A.R. (1983) Determinations of Total Carotenoids and Chlorophylls $a$ and $b$ of Leaf Extracts in Different Solvents. Biochemical Society Transactions, 11, 591-592. https://doi.org/10.1042/bst0110591

[27] Schreiber, U. (2004) Pulse-Amplitude-Modulation (PAM) Fluorometry and Saturation Pulse Method: An Overview. In: Chlorophyll a Fluorescence, Springer, Berlin, 279-319. https://doi.org/10.1007/978-1-4020-3218-9_11

[28] Jassby, A.D. and Platt, T. (1976) Mathematical Formulation of the Relationship between Photosynthesis and Light for Phytoplankton. Limnology and Oceanography, 21, 540-547. https://doi.org/10.4319/lo.1976.21.4.0540

[29] Appenroth, K.-J., Teller, S. and Horn, M. (1996) Photophysiology of Turion Formation and Germination in Spirodela polyrhiza. Biologia Plantarum, 38, 95. https://doi.org/10.1007/BF02879642

[30] Jacobs, D.L. (1947) An Ecological Life-History of Spirodela polyrhiza (Greater Duckweed) with Emphasis on the Turion Phase. Ecological Monographs, 17, 437-469. https://doi.org/10.2307/1948596

[31] Beer, S. (1985) Effects of $\mathrm{CO}_{2}$ and $\mathrm{O}_{2}$ on the Photosynthetic $\mathrm{O}_{2}$ Evolution of Spirodela polyrrhiza Turions. Plant Physiology, 79, 199-201. https://doi.org/10.1104/pp.79.1.199

[32] Perry, T.O. (1968) Dormancy, Turion Formation, and Germination by Different Clones of Spirodela polyrrhiza. Plant Physiology, 43, 1866-1869. https://doi.org/10.1104/pp.43.11.1866

[33] Appenroth, K.-J., Opfermann, J., Hertel, W. and Augsten, H. (1989) Photophysiology of Turion Germination in Spirodela polyrhiza (L.) SCHLEIDEN. II. Influence of After-Ripening on Germination Kinetics. Journal of Plant Physiology, 135, 274-279. https://doi.org/10.1016/S0176-1617(89)80118-X

[34] Appenroth, K.-J., Dathe, W., Hertel, W. and Augsten, H. (1991) Photophysiology of Turion Germination in Spirodela polyrhiza (L.) SCHLEIDEN. VII. Action of Jasmonic Acid. Journal of Plant Physiology, 138, 345-349. https://doi.org/10.1016/S0176-1617(11)80298-1

[35] Oláh, V., Hepp, A. and Mészáros, I. (2016) Assessment of Giant Duckweed (Spirodela polyrhiza L. Schleiden) Turions as Model Objects in Ecotoxicological Applications. Bulletin of Environmental Contamination and Toxicology, 96, 596-601. https://doi.org/10.1007/s00128-016-1765-Z

[36] Park, A., Kim, Y.-J., Choi, E.-M., Brown, M.T. and Han, T. (2013) A Novel Bioassay Using Root Re-Growth in Lemna. Aquatic Toxicology, 140, 415-424. https://doi.org/10.1016/j.aquatox.2013.06.004

[37] Kim, I. (2013) Cellular Features of the Fronds and Turions in Spirodela polyrhiza. Applied Microscopy, 43, 140-145. https://doi.org/10.9729/AM.2013.43.4.140

[38] Kim, I. (2007) Development of the Root System in Spirodela polyrhiza (L.) Schleiden (Lemnaceae). Journal of Plant Biology, 50, 540-547. https://doi.org/10.1007/BF03030707

[39] Kim, I. (2016) Structural Differentiation of the Connective Stalk in Spirodela polyrhiza (L.) Schleiden. Applied Microscopy, 46, 83-88. 
https://doi.org/10.9729/AM.2016.46.2.83

[40] Park, J. and Dinh, T.B. (2019) Contrasting Effects of Monochromatic LED Lighting on Growth, Pigments and Photosynthesis in the Commercially Important Cyanobacterium Arthrospira maxima. Bioresource Technology, 291, Article ID: 121846. https://doi.org/10.1016/j.biortech.2019.121846

[41] Schmid, R. and Dring, M.J. (1992) Circadian Rhythm and Fast Responses to Blue Light of Photosynthesis in Ectocarpus (Phaeophyta, Ectocarpales). Planta, 187, 53-59. https://doi.org/10.1007/BF00201623

[42] Environmental Canada (2007) Guidance Document on Statistical Methods for Environmental Toxicity Tests. EC, Ottawa, Reports EPS 1/RM/46.

[43] Nestler, H., Groh, K.J., Schönenberger, R., Eggen, R.I. and Suter, M.J.-F. (2012) Linking Proteome Responses with Physiological and Biochemical Effects in Herbicide-Exposed Chlamydomonas reinhardtii. Journal of Proteomics, 75, 5370-5385. https://doi.org/10.1016/j.jprot.2012.06.017

[44] Gopalapillai, Y., Vigneault, B. and Hale, B.A. (2014) Root Length of Aquatic Plant, Lemna minor L., as an Optimal Toxicity Endpoint for Biomonitoring of Mining Effluents. Integrated Environmental Assessment and Management, 10, 493-497. https://doi.org/10.1002/ieam.1558

[45] Beaumont, G., Bastin, R. and Therrien, H. (1976) Physiological Effects of Sublethal Doses of Atrazine on Lemna minor L. II. Effect on Photosynthesis and on Respiration. Naturaliste Canadien, 103, 535-541.

[46] Merlin, G., Eulaffroy, P. and Blake, G. (1993) Use of Fluorescence Induction Kinetics of Lemna minor as a Tool for Chemical Stress Evaluation. Science of the Total Environment, 134, 761-772. https://doi.org/10.1016/S0048-9697(05)80080-4

[47] Küster, A. and Altenburger, R. (2007) Development and Validation of a New Fluorescence-Based Bioassay for Aquatic Macrophyte Species. Chemosphere, 67, 194-201. https://doi.org/10.1016/j.chemosphere.2006.08.023

[48] Kumar, K.S. and Han, T. (2011) Toxicity of Single and Combined Herbicides on PSII Maximum Efficiency of an Aquatic Higher Plant, Lemna sp. Toxicology and Environmental Health Sciences, 3, 97-105. https://doi.org/10.1007/s13530-011-0084-3

[49] Murata, N., Takahashi, S., Nishiyama, Y. and Allakhverdiev, S.I. (2007) Photoinhibition of Photosystem II under Environmental Stress. Biochimica et Biophysica Acta (BBA)_Bioenergetics, 1767, 414-421. https://doi.org/10.1016/j.bbabio.2006.11.019

[50] Holbrook, G.P., Beer, S., Spencer, W.E., Reiskind, J.B., Davis, J.S. and Bowes, G. (1988) Photosynthesis in Marine Macroalgae: Evidence for Carbon Limitation. Canadian Journal of Botany, 66, 577-582. https://doi.org/10.1139/b88-083

[51] Juneau, P., Sumitomo, H., Matsui, S., Itoh, S., Kim, S.-G. and Popovic, R. (2003) Use of Chlorophyll Fluorescence of Closterium ehrenbergii and Lemna gibba for Toxic Effect Evaluation of Sewage Treatment Plant Effluent and Its Hydrophobic Components. Ecotoxicology and Environmental Safety, 55, 1-8. https://doi.org/10.1016/S0147-6513(02)00130-6

[52] Hayat, Q., Hayat, S., Alyemeni, M. and Ahmad, A. (2012) Salicylic Acid Mediated Changes in Growth, Photosynthesis, Nitrogen Metabolism and Antioxidant Defense System in Cicer arietinum L. Plant, Soil and Environment, 58, 417-423. https://doi.org/10.17221/232/2012-PSE 


\section{Supplement}

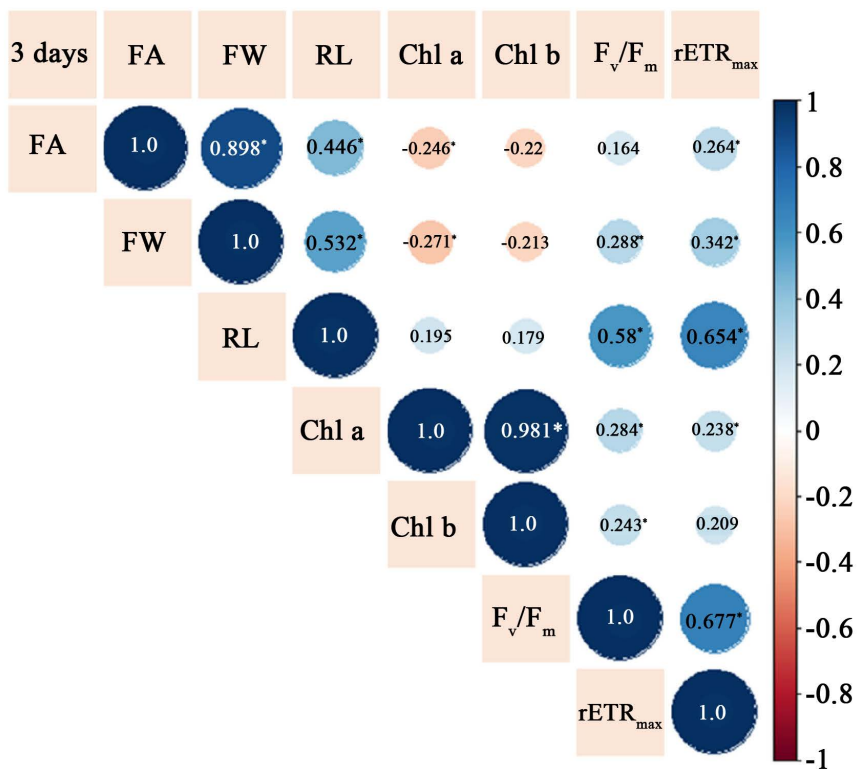

(a)

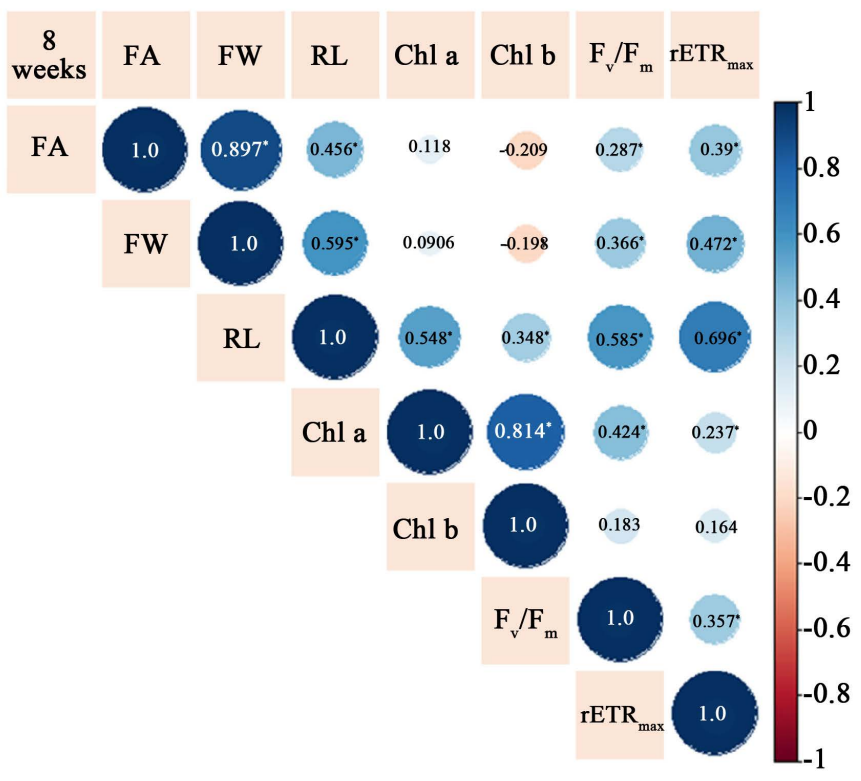

(b)

Figure S1. Matrix view of Pearson's correlations for different parameters in young (a) and mature (b) Spirodela polyrhiza. The color and size of the circles indicate the strength of the correlation. The color bar on the right provides a scale of the correlation coefficients. Light blue, blue and navy colors mean the correlation coefficients are over $0.5,0.7$, and 0.9 , respectively, while the light pink, orange and red color indicates correlation coefficients $<0.5$. The lable within the circle refers to the correlation coefficients values. An asterisk $\left(^{*}\right)$ refers to the statistical significance at the $5 \%$ level. Note that for clear presentation, all matrix views show only the upper portion of the matrix to avoid duplication. FA; relative growth rate of frond area, FW; fresh weight, RL; root regrowth length, Chl a; chlorophyll a content, Chl $b$; chlorophyll $b$ content, $F_{v} / F_{m}$; Optimal quantum yield, $\mathrm{rETR}_{\max }$; the maximum electron transport rate. 